Goldschmidt 2021 Abstract

https://doi.org/10.7185/gold2021.6986

\section{Physico-chemical and biological controls on microbialite formation: experimental biomineralization in open system.}

\author{
ELODIE MULLER ${ }^{1}$, KARIM BENZERARA ${ }^{2}$, ROBIN \\ HAVAS $^{3}$, MIGUEL INIESTO ${ }^{4}$, DIDIER JÉZÉQUEL ${ }^{5}$, \\ PURIFICACIÓN LÓPEZ-GARCÍA ${ }^{6}$, DAVID MOREIRA ${ }^{6}$, \\ ROSALUZ TAVERA $^{7}$, DR. CHRISTOPHE THOMAZO ${ }^{8}$, \\ EMMANUELLE VENNIN $^{9}$ AND NINA ZEYEN $^{10}$ \\ ${ }^{1} \mathrm{CNRS}$ - IMPMC \\ ${ }^{2}$ IMPMC CNRS/Sorbonne Université/MNHN \\ ${ }^{3}$ Université de Bourgogne Franche-Comté \\ ${ }^{4}$ Unité d'Ecologie Systématique et Evolution, CNRS, Université \\ Paris-Saclay, AgroParisTech \\ ${ }^{5}$ Université de Paris-Institut de Physique du Globe de Paris- \\ CNRS, UMR 7154 \\ ${ }^{6}$ Unité d'Ecologie, Systématique et Evolution, CNRS UMR \\ 8079, Université Paris Sud \\ ${ }^{7}$ Departamento de Ecología y Recursos Naturales, Universidad \\ Nacional Autónoma de México \\ ${ }^{8}$ Laboratoire Biogéosciences, UMR CNRS 6282, Université de \\ Bourgogne Franche-Comté \\ ${ }^{9}$ University of Bourgogne Franche-Comté \\ ${ }^{10}$ University of Alberta - EAS \\ Presenting Author: elodie.muller@upmc.fr
}

Microbialites are organo-sedimentary rocks found in modern marine and lacustrine environments, but also in the geological record dated back to $3.5 \mathrm{Ga}$. They represent the oldest undisputed evidence of life on Earth. These rocks are formed by the mediation of microorganisms in interaction with environmental factors and thus represent a source of information on paleobiology and paleoenvironments. However, our ability to recognize and interpret this information depends on our understanding of the relative role of microorganisms and local environmental conditions that control their formation.

Modern lacustrine microbialites from the Trans-Mexican volcanic belt form under a wide diversity of conditions (e.g. alkalinity, $\mathrm{Mg} / \mathrm{Ca}$ ratio, $\mathrm{pH}$, salinity) and show a broad diversity of mineralogical compositions, including various carbonate phases such as hydromagnesite, aragonite, calcite, and monohydrocalcite as well as authigenic Mg-silicates. The varying intensity of microbialite formation and their mineralogical composition appear strongly dependent on the lake hydrochemistry [1]. Meanwhile, Iniesto et al. [2] identified a microbial core of 247 operational taxonomic units (including cyanobacteria and diverse anoxygenic photosynthetic bacteria), which may be involved in microbialite formation and is conserved across lake microbialites, despite their diversity.

Here, in order to better disentangle environmental $v s$. biological controls, we set up a flow-through cell in which we have grown cyanobacterial biofilms under various physicochemical conditions encompassing the conditions of the Mexican lakes. After critical point drying, the biofilms and associated (bio)mineralizations were characterized by SEM (Scanning Electron Microscopy), EDX (energy dispersive X-ray spectrometry) and FTIR (Fourier transform infrared) analyses. The present work explores the local biotic and abiotic factors that may control the mineralogy of lacustrine microbialites.

[1] Zeyen et al. (2017), Procedia Earth and Planetary Science 17, 380-383.

[2] Iniesto et al. (2021), Environmental Microbiology 23(1), 51-68. 